$$
\text { SAND--97-055/C CONF-9706172- }
$$

\title{
STRUCTURE AND OPTICAL PROPERTIES OF RARE EARTH-DOPED ZINC OXYHALIDE TELLURITE GLASSES
}

\author{
D.L. Sidebottom and M.A. Hruschka \\ Dept. of Chemical and Nuclear Engineering \\ University of New Mexico \\ 1001 University Blvd. SE \\ Albuquerque, NM 87106 \\ B.G. Potter and R.K. Brow \\ Sandia National Laboratories \\ P.O. Box 5800-1349 \\ Albuquerque, NM 87185
}

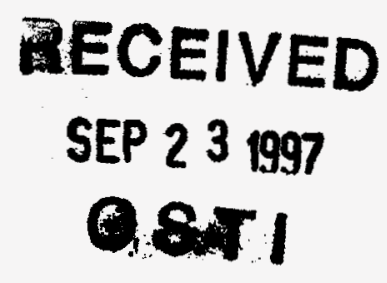

\begin{abstract}
Zinc tellurite glasses appear to be excellent candidates for hosting rare earth ions since they provide a low phonon energy environment to minimize non-radiative losses as well as possess good chemical durability and optical properties. The optical behavior of the rare earth ion can be manipulated by modifying its local environment in the glass host. We report measurements of the emission lifetime, optical absorption, and vibrational density of states of the glass system $(\mathrm{ZnO})_{x}\left(\mathrm{ZnF}_{2}\right)_{y}\left(\mathrm{TeO}_{2}\right)_{1-x-y}$ doped $(0.1 \mathrm{~mol} \%)$ with a series of rare earths. Phonon sideband spectroscopy has been successfully employed to probe vibrational structure in the immediate vicinity of the rare earth ion. We observe a significant increase in the emission lifetime (from approximately $150 \mu$ s to $250 \mu$ s) of $\mathrm{Nd}^{3+}$ with increasing fluorine substitution.
\end{abstract}

KEYWORDS: Tellurite glasses, halide substitution, rare earth ions, optical properties

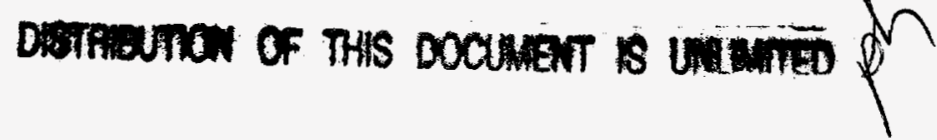




\section{DISCLAIMER}

This report was prepared as an account of work sponsored by an agency of the United States Government. Neither the United States Government nor any agency thereof, nor any of their employees, make any warranty, express or implied, or assumes any legal liability or responsibility for the accuracy, completeness, or usefulness of any information, apparatus, product, or process disclosed, or represents that its use would not infringe privately owned rights. Reference herein to any specific commercial product, process, or service by trade name, trademark, manufacturer, or otherwise does not necessarily constitute or imply its endorsement, recommendation, or favoring by the United States Government or any agency thereof. The views and opinions of authors expressed herein do not necessarily state or reflect those of the United States Government or any agency thereof. 


\section{DISCLAMIER}

Portions of this document may be illegible in electronic image produets. Images are produced from the best available original document. 


\section{Introduction}

Rare earth ions possess optical transitions within the $4 \mathrm{f}$ level structure which are critical for the development of optical amplifiers and phosphors[1]. Both radiative and non-radiative processes which mediate the excited state decay within the $4 \mathrm{f}$ level are sensitive to the host material[2,3]. A significant contribution to the measured emission lifetime, a key parameter of device performance, results from multiphonon[4], nonradiative relaxation.

As a general rule, the non-radiative loss is dominated by the highest energy phonons available in the matrix. Consequently, it important to select a host material for which the maximum phonon energy is as low as possible. In silica, this phonon energy is reasonably large (about $1100 \mathrm{~cm}^{-1}$ ) and for chalcogenide glasses it is quite low (about 300 $\left.\mathrm{cm}^{-1}\right)[5]$. Although chalcogenide glasses possess the lower phonon energy, they lack many of the desirable features of silica-based glasses, including mechanical strength and chemical durability.

Tellurite glasses represent a compromise between the desire for a low phonon energy host coupled with the need to retain mechanical strength and low process temperatures. They also exhibit low optical absorption at visible and infrared wavelengths[5-7]. In this paper, we report measurements of the optical properties of several rare earth ions doped into zinc tellurite glasses. Our experimental probes include Raman scattering, optical absorption, phonon sideband spectroscopy and emission lifetime spectroscopy. Our goal is to develop an increased insight into the manipulation of the local structural environment and its influence on both radiative and non-radiative deexcitation of the rare earth dopant population. The effects of structural depolymerization through $\mathrm{ZnO}$ addition and halide substitution $\left(\mathrm{ZnF}_{2}\right)$ are investigated.

\section{Experimental}


Samples of $\mathrm{ZnO}-\mathrm{TeO}_{2}$ glass were prepared by melting $\mathrm{ZnO}$ and $\mathrm{TeO}_{2}$ powders in a gold crucible for approximately 1 hour at about $800^{\circ} \mathrm{C}$ in air. Halide-substituted samples prepared using $\mathrm{ZnF}_{2}$ powder required lower melt temperatures $\left(\approx 650^{\circ} \mathrm{C}\right)$ but, owing to a tendency for the halide to react with gold, were melted in silica crucibles. Final compositions were determined $( \pm 10 \%$ relative) by X-ray photoelectron spectroscopy. The glass forming range was determined by visual inspection and X-ray powder diffraction analysis. The glass samples were generally transparent at visible wavelengths with an ultraviolet (UV) cutoff ( $50 \%$ transmittance) at around $380 \mathrm{~nm}$. Glass transition and crystallization temperatures were determined using differential thermal analysis and found to be reproducible to $\pm 5^{\circ} \mathrm{C}[8]$. The $\mathrm{xZnO}-(1-\mathrm{x}) \mathrm{TeO}_{2}$ glass forming range $[9,10]$ was determined to be $0.2 \leq x \leq 0.4$, and could be increased to $x \approx 0.6$ by halide substitution. Doped glasses were obtained by addition of the desired rare earth oxide to the melt. For optical investigations, the doping levels were generally varied in an isostructural manner by adding optically inactive lutetium together with the optically active ion so as to maintain $1 \mathrm{~mol} \%$ total rare earth. However, in some halide substituted situations, only $0.1 \mathrm{~mol} \%$ (total) of optically active rare earth was used due to limited solubility.

Optical characterization included optical absorption, Raman scattering, spectral and temporal photoluminescence, and photoluminescence excitation (phonon sideband) measurements. Absorption measurements were performed in transmission mode at wavelengths from $200 \mathrm{~nm}$ to $3000 \mathrm{~nm}$ (Perkin-Elmer Lambda 900). Raman scattering was performed with an $\mathrm{Ar}^{+}$laser (514.5 nm, approx. $200 \mathrm{~mW}$ ) and a Spex 1877 Triplemate 
spectrometer with a typical spectral resolution of about $2 \mathrm{~cm}^{-1}$. Fluorescence spectra were collected using an $\mathrm{Ar}^{+}$laser (488 nm) focussed to an approximately $100 \mu \mathrm{m}$ incident spot size and a $0.275 \mathrm{~m}$ grating spectrometer (ARC) with a $2 \mathrm{~nm}$ resolution. The emitted light intensity was detected by either a cooled photomutiplier tube (Hamamatsu R2658) or a $\mathrm{LN}_{2}$-cooled, Ge detector (North Coast). For measurements of the fluorescence lifetime, the excitation intensity was provided by a $\mathrm{N}_{2}$-pumped dye laser operating at a wavelength of $520 \mathrm{~nm}$ which delivered $1 \mathrm{~ns}$ pulses of about $150 \mu \mathrm{J}$ at a $10 \mathrm{~Hz}$ repetition rate. Phonon sideband measurements were performed using a tunable source comprised of a $400 \mathrm{~W}$ Xe lamp and $0.15 \mathrm{~m}$ monochrometer (ARC) with a spectral resolution of $1 \mathrm{~nm}$. The emitted intensity was measured using the $0.275 \mathrm{~m}$ spectrometer described previously.

\section{Theoretical Background}

The success of many optical devices which rely upon rare earth ion transitions is controlled in part by achieving appropriate decay lifetimes for a given excited state level. In lasing applications, for example, one desires to maximize the lifetime $\left(\tau_{\mathrm{M}}\right)$ of the upper excited state and minimize the lifetime of the lower state. Thus, a major research goal is to develop strategies for manipulating the lifetime of a given excited state. The decay rate for an excited state population, $\Gamma_{\mathrm{M}}=1 / \tau_{\mathrm{M}}$, is comprised of two processes: the intrinsic radiative decay rate $\left(\Gamma_{\mathrm{R}}\right)$ and the non-radiative decay $\left(\Gamma_{\mathrm{NR}}\right)$ due to multiphonon loss. The radiative decay rate is influenced by variations of the local crystal field symmetry at the rare earth site. These variations are determined by the host matrix into which the ion is placed. In addition to changes in field symmetry, the local vibrational density of states of the host also 
provides a mechanism for depopulation of the excited state energy. Electron-phonon coupling allows an excited rare earth ion to decay non-radiatively via the production of lattice vibrations[4]. Naturally, this non-radiative process from the upper level is unattractive for amplifying devices which rely upon achieving and maintaining a population inversion.

The total decay rate is thus

$$
\Gamma_{M}=\Gamma_{R}+\Gamma_{N R}+\Gamma_{Q}=\frac{1}{\tau_{R}}+\frac{1}{\tau_{N R}}+\frac{1}{\tau_{Q}}
$$

where $\Gamma_{\mathrm{Q}}$ represents an additional non-radiative loss mechanism referred to as quenching. Quenching involves the transfer of excited state energy between rare earth ions that terminates when the energy encounters a defect or trap. For low ion concentrations, as considered in the present paper, this third process is negligible (i.e., $\Gamma_{\mathrm{Q}}=0$ ).

Determination of the intrinsic radiative decay rate, $\Gamma_{R}$, was accomplished through a Judd-Ofelt $[3,11]$ analysis of the absorption spectra. The Judd-Ofelt theory allows one to estimate the radiative decay rate of all excited states as well as predict oscillator strengths and branching ratios using the experimentally observed absorption curves. These oscillator strengths can be expressed under certain simplifying conditions as a linear sum of standard transition matrix elements involving so-called Judd-Ofelt $(\mathrm{JO})$ parameters $\left(\Omega_{\mathrm{q}}(\mathrm{q}=2,4,6)\right)$ whose values are directly influenced by the host matrix and provide a qualitative measure of the asymmetry of the local electrostatic field near the rare earth ion[3]. Errors in the determination of $\Gamma_{R}$ are no larger than about $20 \%[12]$. 
Using values of $\Gamma_{R}$ from the Judd-Ofelt analysis together with the experimentally

observed excited state decay rate, $\Gamma_{\mathrm{M}}$, the non-radiative contribution, $\Gamma_{\mathrm{NR}}$, can be determined. This non-radiative contribution arises from the production of lattice vibrations (optical phonons). The probability for this process to occur is determined by the strength of the electron-phonon coupling, $g$, and number of phonons of energy $\hbar \omega, \mathrm{p}=\mathrm{E}_{\mathrm{g}} / \hbar \omega$, required to bridge the energy gap, $\mathrm{E}_{\mathrm{g}}$, to the next lowest available electronic energy level. The highest energy phonons dominate this process as this allows the number of phonons involved in the deexcitation to be minimized. As the energy gap to the next lowest energy level decreases, the number of phonons needed to bridge that gap also decreases and the probability for non-radiative decay increases. A phenomenological theory of multiphonon decay has been developed[13-15], which predicts an energy gap dependence of the form

$$
\Gamma_{N R}=A e^{-\alpha E_{g}},
$$

where $\alpha$ and $A$ are phenomenological parameters which indicate the sensitivity of $\Gamma_{\mathrm{NR}}$ to $E_{g}$, and the value of $\Gamma_{N R}$ in the limit of vanishing $E_{g}$, respectively. The parameters $\alpha$ and $A$ are specific to a given host and can be compared with those obtained from other glass systems to evaluate the relative contribution of multiphonon decay in the deexcitation of $4 \mathrm{f}$ energy levels.

Additional information regarding the non-radiative loss mechanism can be inferred from the temperature dependence of $\Gamma_{\mathrm{NR}}$. Since phonons are classically described by BoseEinstein statistics, the occupation probability of phonons with a particular energy $\hbar \omega_{i}$ is given by 


$$
n_{i}=\left(e^{\hbar \omega_{i} / k T}-1\right)^{-1}
$$

The rate of phonon emission is proportional to this occupation probability, and for a set of available phonon energies $(i=1,2,3, \ldots)$ is given by $[16]$

$$
\Gamma_{N R}(T)=\Gamma_{N R}(0) \prod_{i}\left(n_{i}+1\right)^{p_{i}}=\Gamma_{N R}(0) \prod_{i}\left(1-e^{-\hbar \omega_{i} / k T}\right)^{-p_{i}}
$$

where $p_{i}$ is the number of phonons with energy $\hbar \omega_{i}$ which participate in the decay of the excited electron. By fitting this expression to experimentally observed $\Gamma_{\mathrm{NR}}(T)$ one can obtain a more complete picture of the non-radiative process.

\section{Results}

Raman spectra collected from a series of $\mathrm{xZnO}-(1-\mathrm{x}) \mathrm{TeO}_{2}$ glasses are shown in Fig. 1. Three individual modes are distinguished: a broad mode at about $430 \mathrm{~cm}^{-1}$ and two narrower modes occurring at $670 \mathrm{~cm}^{-1}$ and $740 \mathrm{~cm}^{-1}$. All the spectra have been normalized to the maximum intensity (near $740 \mathrm{~cm}^{-1}$ ) and are reproducible to within the thickness of the spectral curves drawn in the figure. The relative intensity of the $430 \mathrm{~cm}^{-1}$ and $670 \mathrm{~cm}^{-1}$ modes decreases with the addition of $\mathrm{ZnO}$, and the mode near $740 \mathrm{~cm}^{-1}$ shifts to slightly higher energy.

Phonon sideband (PSB)[17] measurements were conducted on $25 \mathrm{ZnO}-74 \mathrm{TeO}_{2}-$ $1 \mathrm{Eu}_{2} \mathrm{O}_{3}$. In the experiment, the excitation wavelength is varied in the vicinity of the $\mathrm{Eu}^{3+}$ ${ }^{5} \mathrm{D}_{2}$ absorption band (occurring at $465 \mathrm{~nm}$ ) and the emission from the ${ }^{5} \mathrm{D}_{0}$ to ${ }^{7} \mathrm{~F}_{0}$ levels is monitored at $615 \mathrm{~nm}$. Intensity maxima occur not only for the direct absorption at $465 \mathrm{~nm}$, but also near $450 \mathrm{~nm}$ and $460 \mathrm{~nm}$. These latter maxima represent the production of phonons near the rare earth ion in conjunction with excitation from the ground state. In Fig. 2, our PSB results are presented as an energy shift relative to the direct absorption 
which occurs at $465 \mathrm{~nm}$ excitation. The error in the measurement is comparable to the size of the data symbol. Included in the figure for comparison is the Raman spectrum for $25 \mathrm{ZnO}-75 \mathrm{TeO}_{2}$. We observe two phonon bands; one near $700 \mathrm{~cm}^{-1}$ and the other near 300 $\mathrm{cm}^{-1}$ that is evident as a shoulder on the direct absorption peak.

Figure 3 shows a typical absorption spectrum $\left(25 \mathrm{ZnO}-74 \mathrm{TeO}_{2}-1 \mathrm{Nd}_{2} \mathrm{O}_{3}\right)$. The UV cutoff is evident at the left of the figure and several absorption lines are observed. The assignment of these absorption bands to specific electron transition levels has been based upon comparison with previous absorption studies of $\mathrm{Nd}$-doped materials published in the literature[2]. The error in the absorption spectra are again comparable to the line thickness shown in the figure and are reproducible between different melts of the same composition.

Using absorption spectra such as the example shown in Fig. 3, Judd/Ofelt (JO) analysis was performed to determine the radiative decay rate, $\Gamma_{\mathrm{R}}$. A series of emission lifetime measurements were performed on $25 \mathrm{ZnO}-74 \mathrm{TeO}_{2}-0.9 \mathrm{La}_{2} \mathrm{O}_{3}-0.1 \mathrm{RE}_{2} \mathrm{O}_{3}$ using $\mathrm{RE}=$ $\mathrm{Nd}, \mathrm{Ho}, \mathrm{Tm}$, and Er to examine the variation of the non-radiative decay rate, $\Gamma_{\mathrm{NR}}$, with energy gap to the next lower level, $\mathrm{E}_{\mathrm{g}}$. The $0.1 \mathrm{~mol} \% \mathrm{RE}_{2} \mathrm{O}_{3}$ doping level was selected based upon preliminary study of the concentration dependence of $\Gamma_{M}$ for $\mathrm{Nd}$-doped zinc tellurite glasses which indicated this concentration is well below the quenching threshold. Results are shown in Fig. 4 and are compared with previously published results[2] for a silicate glass. A least squares fit of the data to Eq. (4), shown in Fig. 4, resulted in $\alpha=$ $3.0 \times 10^{-3}\left( \pm 1.0 \times 10^{-3}\right) \mathrm{cm}$. We find an overall decrease in $\Gamma_{\mathrm{NR}}$ for the present tellurite glass as compared with the silicate as well as a lower slope. This decrease of the nonradiative rate is anticipated in light of the lower maximum phonon energy of the tellurite matrix (see Fig. 1).

The temperature dependence of $\Gamma_{M}$ was measured for the ${ }^{4} I_{11 / 2}$ to ${ }^{4} I_{15 / 2}$ transition occurring in $25 \mathrm{ZnO}-74.9 \mathrm{TeO}_{2}-0.1 \mathrm{Er}_{2} \mathrm{O}_{3}$ at about $980 \mathrm{~nm}$. The next lower energy level is 
the ${ }^{4} \mathrm{I}_{13 / 2}$ occurring about $3710 \mathrm{~cm}^{-1}$ below the ${ }^{4} \mathrm{I}_{11 / 2}$. Data were collected from about $20 \mathrm{~K}$ up to temperatures just below the glass transition and from these measured values of $\Gamma_{M}$, together with the radiative decay rate determined from our JO analysis, $\Gamma_{\mathrm{NR}}(\mathrm{T})$ was determined as shown in Fig. 5. The error is comparable to the size of the data symbol. The non-radiative lifetime is $430( \pm 20) \mu$ s a low temperatures but decreases to $120( \pm 10)$ $\mu$ s at $500 \mathrm{~K}$.

Lastly we examine the effect of halide substitution upon the excited state decay rate. We have performed emission lifetime measurements for the ${ }^{4} \mathrm{~F}_{3 / 2}$ excited state on four samples doped with $0.1 \mathrm{~mol} \% \mathrm{Nd}_{2} \mathrm{O}_{3}$. These include two samples containing no fluorine but for which the $\mathrm{Zn} / \mathrm{Te}$ ratio is changed (A: $25 \mathrm{ZnO}-74.9 \mathrm{TeO}_{2}-0.1 \mathrm{Nd}_{2} \mathrm{O}_{3}$ and $\mathrm{D}: 35 \mathrm{ZnO}$ 64.9 $\left.\mathrm{TeO}_{2}-0.1 \mathrm{Nd}_{2} \mathrm{O}_{3}\right)$ and two containing fluorine (B: $14.9 \mathrm{ZnO}-23.4 \mathrm{ZnF}_{2}-61.6 \mathrm{TeO}_{2}-$ $0.1 \mathrm{Nd}_{2} \mathrm{O}_{3}$ and $\mathrm{C}: 17.3 \mathrm{ZnO}-37.8 \mathrm{ZnF}_{2}-44.8 \mathrm{TeO}_{2}-0.1 \mathrm{Nd}_{2} \mathrm{O}_{3}$ ). Attempts were made to maintain a fixed $\mathrm{Zn} / \mathrm{Te}$ ratio in the fluorine-doped samples, however, due to processing difficulties, the final compositions which were obtained often deviated (within 15\%) from the batch composition. The emission decay for samples A, B and C are shown in Fig. 5 and emission lifetimes were determined by a least squares fit to a single exponential. The figure shows that the measured lifetime increases substantially with the introduction of fluorine into the tellurite matrix, increasing from about $150 \mu$ s in sample $A$ to more than $250 \mu$ s in sample $\mathrm{C}$. The measured lifetime determined from sample $\mathrm{D}(166 \pm 10 \mu \mathrm{s})$ was unchanged from that seen for sample $\mathrm{A}$, indicating that the increased lifetimes seen for samples $\mathrm{B}$ and $\mathrm{C}$ are indeed due to the presence of fluorine and not merely a result of changes occurring in the $\mathrm{Zn} / \mathrm{Te}$ ratio.

\section{Discussion}


The Raman spectra shown in Fig. 1 demonstrate how addition of $\mathrm{ZnO}$ modifies the global tellurite network. In addition to the bending mode at $430 \mathrm{~cm}^{-1}$, the two high energy bands in the figure have previously been assigned to the symmetric stretch of $\mathrm{Te}-\mathrm{O}$ bonds in $\mathrm{TeO}_{4}$, a trigonal bipyramid possessing lone pair electrons $\left(670 \mathrm{~cm}^{-1}\right)$, and to the symmetric stretch of the so-called $\mathrm{TeO}_{3+1}$ unit $\left(740 \mathrm{~cm}^{-1}\right)$ which resembles the $\mathrm{TeO}_{4}$ unit except the axial bond length for one oxygen is larger[9]. Also included in this second peak, toward the high energy side, are $\mathrm{TeO}_{3}$ units. With the addition of $\mathrm{ZnO}$ the $\mathrm{Te}-\mathrm{O}-\mathrm{Te}$ network becomes increasingly more depolymerized as $\mathrm{TeO}_{4}$ is converted to $\mathrm{TeO}_{3}$. This depolymerization causes the ratio of $\mathrm{TeO}_{4}$ to $\mathrm{TeO}_{3}$ and $\mathrm{TeO}_{3+1}$ units to decrease as is evidenced by the shifting Raman intensities in Fig. 1. Also evident in the figure is a slight shift of the band at $740 \mathrm{~cm}^{-1}$ to higher energy which is consistent with the conversion of $\mathrm{TeO}_{3+1}$ to $\mathrm{TeO}_{3}$ units[9].

These Raman measurements provide a picture of the vibrational density of states in the glass averaged over its entirety. Depending upon the local bonding environment of the rare earth ion within the matrix, some of these vibrational modes may or may not be coupled to electronic excited states. Information about the local vibrational density of states (DOS) is conveyed by the phonon sideband (PSB) results found in Fig. 2. In the figure, the local vibrational density of states as obtained from the PSB intensity is compared with the global DOS obtained from Raman scattering. Two sidebands are visible as a band at about $700 \mathrm{~cm}^{-1}$ and a shoulder at about $300 \mathrm{~cm}^{-1}$, resting atop the tail of the direct absorption line. The energies of these features compare favorably with those observed by Raman scattering. The major difference occurs in the low energy band which occurs with an energy $40 \%$ reduced over that of the undoped glass. It has been argued[18] that due to the larger effective mass of the rare earth ion, peak frequencies in PSB spectra will be shifted to lower energies in comparison with infrared and Raman measurements in the ionfree glass. However, in sodium silicate glasses[18] this shift was only about 5\%. In our instance, the high energy modes clearly are not shifted to the extent that the lower energy 
modes appear to be shifted. Instead, it appears that the PSB spectra agree more closely with Raman modes seen by Burger[9] in crystalline forms of $\mathrm{Zn}_{2} \mathrm{Te}_{3} \mathrm{O}_{8}$ and $\mathrm{ZnTeO}$ assigned to $\mathrm{TeO}_{4}$ and $\mathrm{TeO}_{3}\left(790,690,400,360\right.$ and $\left.310 \mathrm{~cm}^{-1}\right)$ and $\mathrm{TeO}_{3+1}\left(740 \mathrm{~cm}^{-1}\right)$ units. To illustrate this we have performed a deconvolution of our PSB spectrum into six modes (assuming a Gaussian lineshape in each case) occurring at energies approximately 5\% lower than those seen by Burger. While such a deconvolution is not particularly robust as it involves numerous fitting parameters, it is not our intention to extract quantitative information from these fit parameters. Rather, we merely wish to demonstrate that this set of six modes does succeed in accounting for specific features in the PSB spectra, particularly the slight excess intensity occurring at $705 \mathrm{~cm}^{-1}$ that corresponds to the $\mathrm{TeO}_{3+1}$ mode.

The ratio of integrated intensity of the phonon sideband to that of the direct absorption peak provides a direct measure of the electron-phonon coupling strength. Using the integrated areas of the deconvolution discussed above, we find $\mathrm{g}=0.02$ and $\mathrm{g}=0.01$ $( \pm 0.002)$ for the bands near $700 \mathrm{~cm}^{-1}$ and $300 \mathrm{~cm}^{-1}$, respectively. we These values are comparable to similar estimates found in the literature for other glasses[18].

Next we examine the effect of this local vibrational DOS upon the non-radiative decay rate. We first attempted to fit the temperature dependence of the non-radiative lifetime shown in Fig. 5 using Eq. (4) assuming the participation of a single phonon energy. Our best fit indicated $\hbar \omega=467( \pm 30) \mathrm{cm}^{-1}$ and $\mathrm{p}=3.9( \pm 0.3)$. Although this energy corresponds well with the deformation mode seen in the Raman studies, the result contradicts the expected result corresponding to the maximum phonon energy available. As a further indication that this single phonon approach is inappropriate, we note that our fit result does not satisfy conservation of energy since four phonons of energy $470 \mathrm{~cm}^{-1}$ only account for $1880 \mathrm{~cm}^{-1}$, substantially short of the gap energy $\left(3710 \pm 200 \mathrm{~cm}^{-1}\right)$.

In our second fitting attempt, we allowed only two phonon energies and fixed those energies from the mean of the local vibrational DOS provided by our PSB measurements; 
$\hbar \omega_{1}=320( \pm 50) \mathrm{cm}^{-1}$ and $\hbar \omega_{2}=700( \pm 50) \mathrm{cm}^{-1}$. Our best fit to the data yielded $\mathrm{p}_{1}=$ $1.1( \pm 0.2)$ and $p_{2}=4.8( \pm 0.2)$. In this case conservation of energy appears to be maintained since $p_{1} \hbar \omega_{1}+p_{2} \hbar \omega_{2}=3710 \mathrm{~cm}^{-1}$ is in good agreement with the energy gap. Furthermore this fit result is consistent with the notion that the highest energy phonon dominates the multiphonon decay process, since there is roughly a five-to-one ratio of high energy phonons to low energy phonons.

As demonstrated in Fig. 6, we found significant increase in the emission lifetime of the ${ }^{4} \mathrm{~F}_{3 / 2}$ state of $\mathrm{Nd}^{3+}$ with increasing halide substitution. The energy gap for this particular transition is large (about $5000 \mathrm{~cm}^{-1}$ ) and we anticipate $\Gamma_{\mathrm{NR}}$ is negligible. To determine the radiative lifetime for these samples, Judd-Ofelt analysis was performed. Values of $\tau_{R}$ (A:

$164 \mu \mathrm{s}, \mathrm{B}: 203 \mu \mathrm{s}, \mathrm{C}: 254 \mu \mathrm{s}, \mathrm{D}: 153 \mu \mathrm{s})$ are all within $5 \%$ of $\tau_{\mathrm{M}}$ and appear to account for the increase in the total emission lifetime that we observe. This is clear evidence that halide substitution does significantly modify the local electrostatic field symmetry of the rare earth ion and can produce a substantial increase of the intrinsic radiative lifetime.

At present it is unclear how the inclusion of fluorine into the tellurite matrix specifically modifies the local environment of the rare earth ion. Owing to their large size, rare earth ions possess a high coordination number and we speculate that (given its similar ionic radius) the fluorine ion replaces an oxygen ion somewhere in this coordination sphere, sufficiently disturbing the local electron density so as to alter the electrostatic environment of the rare earth.

\section{Summary}

Zinc tellurite glasses are a suitable host for optically active rare earth ions as they provide a low multiphonon loss. Phonon sideband measurements reveal a local vibrational density of states that is comparable to that obtained globally from Raman spectroscopy but 
which exhibits some distinctive differences. In particular, the lowest energy PSB is about $40 \%$ less in energy as compared with the deformation mode seen in the glass. We find that the local vibrational modes obtained in PSB conform to vibrational analogues seen in crystalline phases of zinc tellurite. The mean energies of the two main PSB peaks account well for the observed temperature dependence of multiphonon processes in the zinc tellurite glasses studied so far. Fluorine substitution is shown to affect the local crystal field symmetry of the rare earth ion and result in substantial increases in its radiative lifetime.

B.G.P. and R.K.B. acknowledge the resources of Sandia National Laboratories. Sandia is a multiprogram laboratory operated by Sandia Corporation, a Lockheed Martin Company, for the United States Department of Energy under Contract DE-AC04-94AL85000.

\section{REFERENCES}

[1] Optical Fibre Lasers and Amplifiers, ed. by P.W. France (CRC Press, Boca Raton, FL 1991).

[2] R. Reisfeld and C.K. Jorgensen in Lasers and Excited States of Rare Earths, (Springer-Verlag, Berlin 1977).

[3] R.D. Peacock, Structure and Bonding 22 (1975) 83.

[4] T. Miyakawa and D.L. Dexter, Phys. Rev. B1 (1970) 2961.

[5] J.S. Wang, E.M. Vogel, and E. Snitzer, Opt. Mats. 3 (1994) 187.

[6] C. Brecher, L.A. Riseberg, and M.J. Weber, Phys. Rev. B18 (1978) 5799.

[7] M.J. Weber, J. Non-Cryst. Sol. 123 (1990) 208.

[8] M.A. Hruscka, D.L. Sidebottom, R.K. Brow, and B.G. Potter, to be published.

[9] H. Burger, K. Kneipp, H. Hobert, W. Vogel, V. Kozhukharov, and S. Neov, J. Non-Cryst. Sol. 151 (1992) 134.

[10] D.L. Sidebottom, M.A. Hruscka, B.G. Potter, R.K. Brow, and J.J. Hudgens, in press.

[11] B.R. Judd, Phys. Rev. 127 (1962) 750; G.S. Ofelt, J. Chem. Phys. 37 (1962) 511.

[12] M.J. Weber, J. Chem. Phys. 48 (1968) 4774.

[13] T. Miyakawa and D.L. Dexter, Phys. Rev. B1 (1970) 2961.

[14] L.A. Riseberg and H.W. Moos, Phys. Rev. 174 (1968) 429.

[15] S. Tanabe, S. Todoroki, K. Hirao, and N. Soga, J. Non-Cryst. Sol. 122 (1990) 59. 
R. Reisfeld, Structure and Bonding 22 (1975) 123.

[17] S. Tanabe, K. Hirao, and N. Soga, J. Non-Cryst. Sol. 142 (1992) 148.

[18] S. Todoroki, S. Tanabe, K. Hirao, and N. Soga, J. Non-Cryst. Sol. 136 (1991) 213.

FIGURE CAPTIONS

Fig. 1 Raman scattering spectra for a selection of zinc tellurite glasses.

Fig. 2 Phonon Sideband intensity for $25 \mathrm{ZnO}-74 \mathrm{TeO}_{2}-1 \mathrm{Eu}_{2} \mathrm{O}_{3}$ compared with Raman intensity for $25 \mathrm{ZnO}-75 \mathrm{TeO}_{2}$. In addition to the peak at $700 \mathrm{~cm}^{-1}$ there is a lower energy peak near $300 \mathrm{~cm}^{-1}$. The solid lines represent the deconvolution of the PSB intensity into six vibrational modes described by Burger[9] and discussed in the text.

Fig. 3 Absorptance spectrum for $25 \mathrm{ZnO}-74 \mathrm{TeO}_{2}-1 \mathrm{Nd}_{2} \mathrm{O}_{3}$.

Fig. 4 Variation of the non-radiative decay rate (closed symbols) with energy gap to the next lowest level in $25 \mathrm{ZnO}-74.9 \mathrm{TeO}_{2}-0.1 \mathrm{RE}_{2} \mathrm{O}_{3}(\mathrm{RE}=\mathrm{Nd}, \mathrm{Ho}, \mathrm{Tm}, \mathrm{Er})$. Open symbols are from the literature[2] for $\mathrm{SiO}_{2}$. The solid lines are fits to Eq.(2).

Fig. 5 Temperature dependence of the non-radiative lifetime for the ${ }^{4} \mathrm{I}_{11 / 2}$ state in $25 \mathrm{ZnO}$ 74.9 $\mathrm{TeO}_{2}-0.1 \mathrm{Er}_{2} \mathrm{O}_{3}$. Solid line is a two phonon fit to Eq. (5) which is discussed in the text.

Fig. 6 The measured emission decay from the ${ }^{4} \mathrm{~F}_{3 / 2}$ for three glasses of varying fluorine content (A: $25 \mathrm{ZnO}-74.9 \mathrm{TeO}_{2}-0.1 \mathrm{Nd}_{2} \mathrm{O}_{3}, \mathrm{~B}: 14.9 \mathrm{ZnO}-23.4 \mathrm{ZnF}_{2}-61.6 \mathrm{TeO}_{2}$ $0.1 \mathrm{Nd}_{2} \mathrm{O}_{3}$ and $\mathrm{C}: 17.3 \mathrm{ZnO}-37.8 \mathrm{ZnF}_{2}-44.8 \mathrm{TeO}_{2}-0.1 \mathrm{Nd}_{2} \mathrm{O}_{3}$ ). The measured emission lifetime is shown in parentheses. 


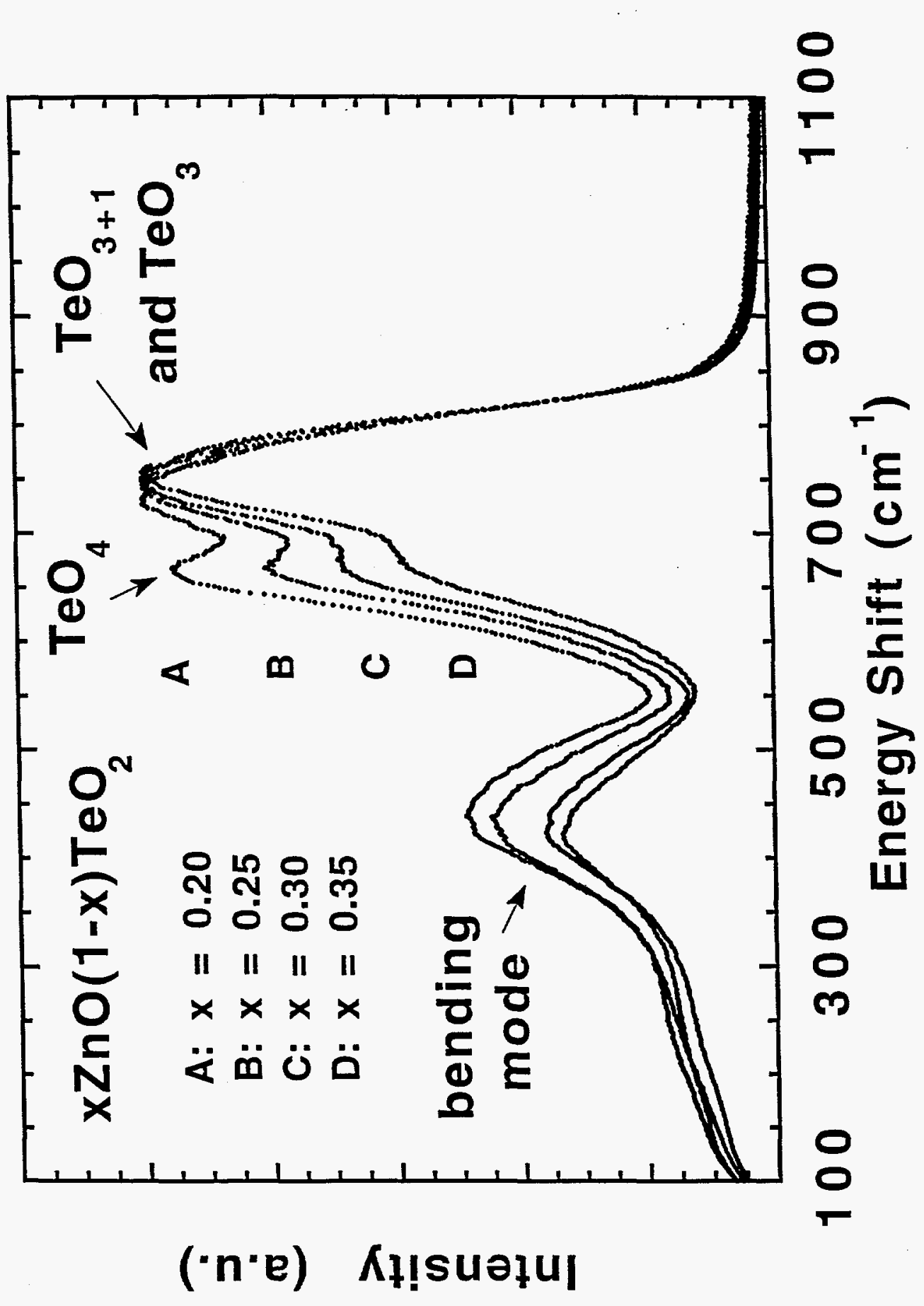




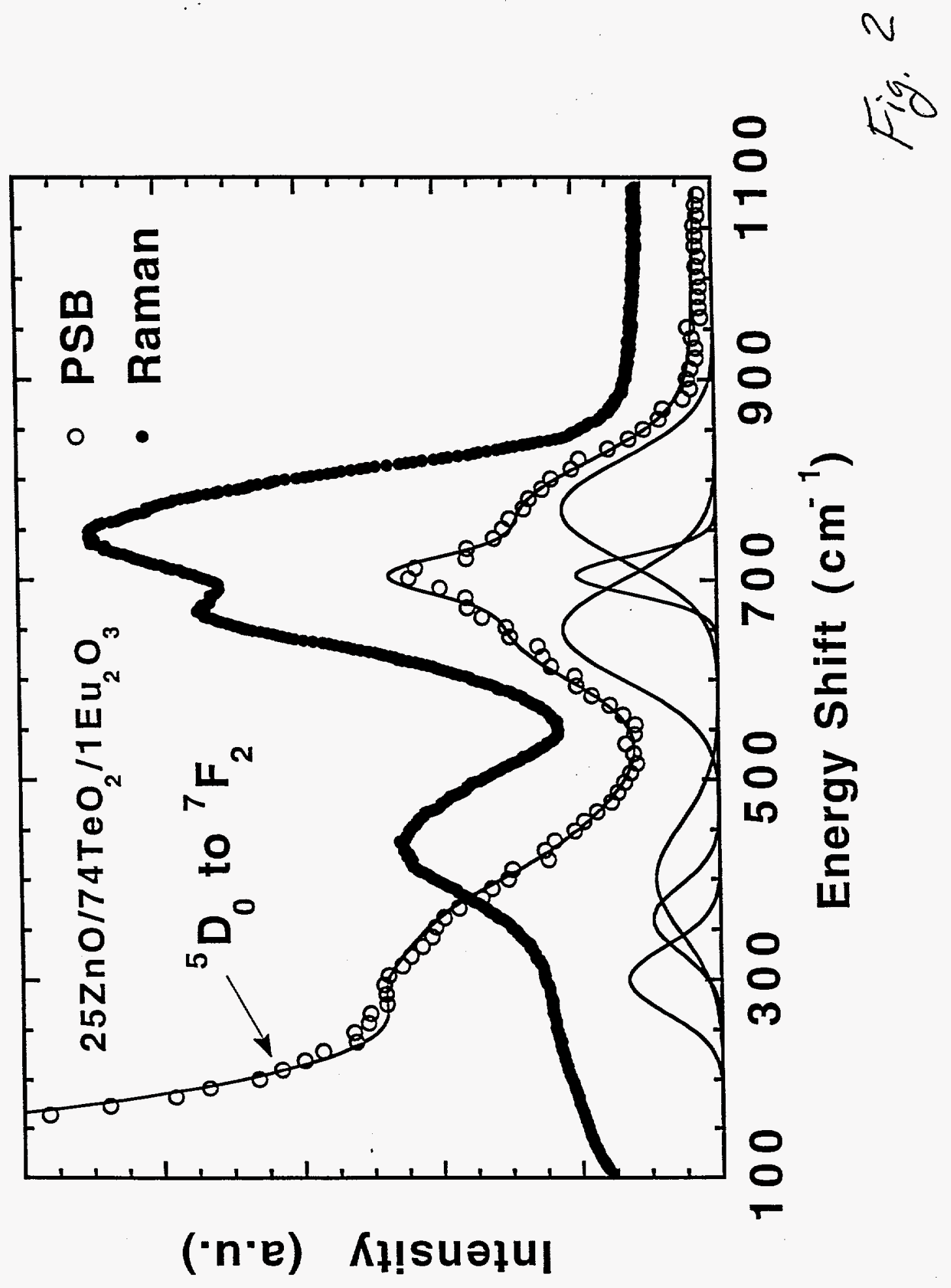




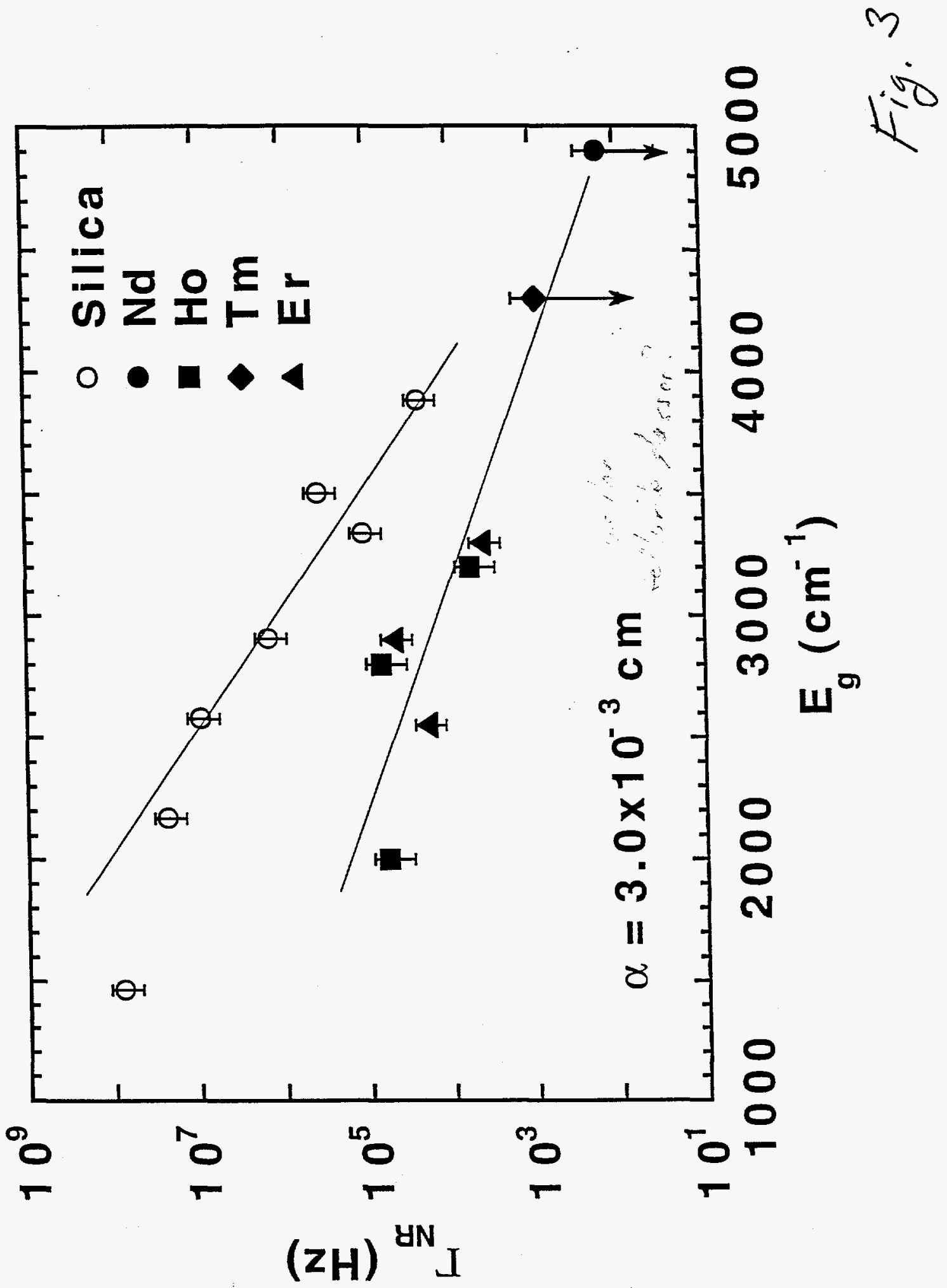




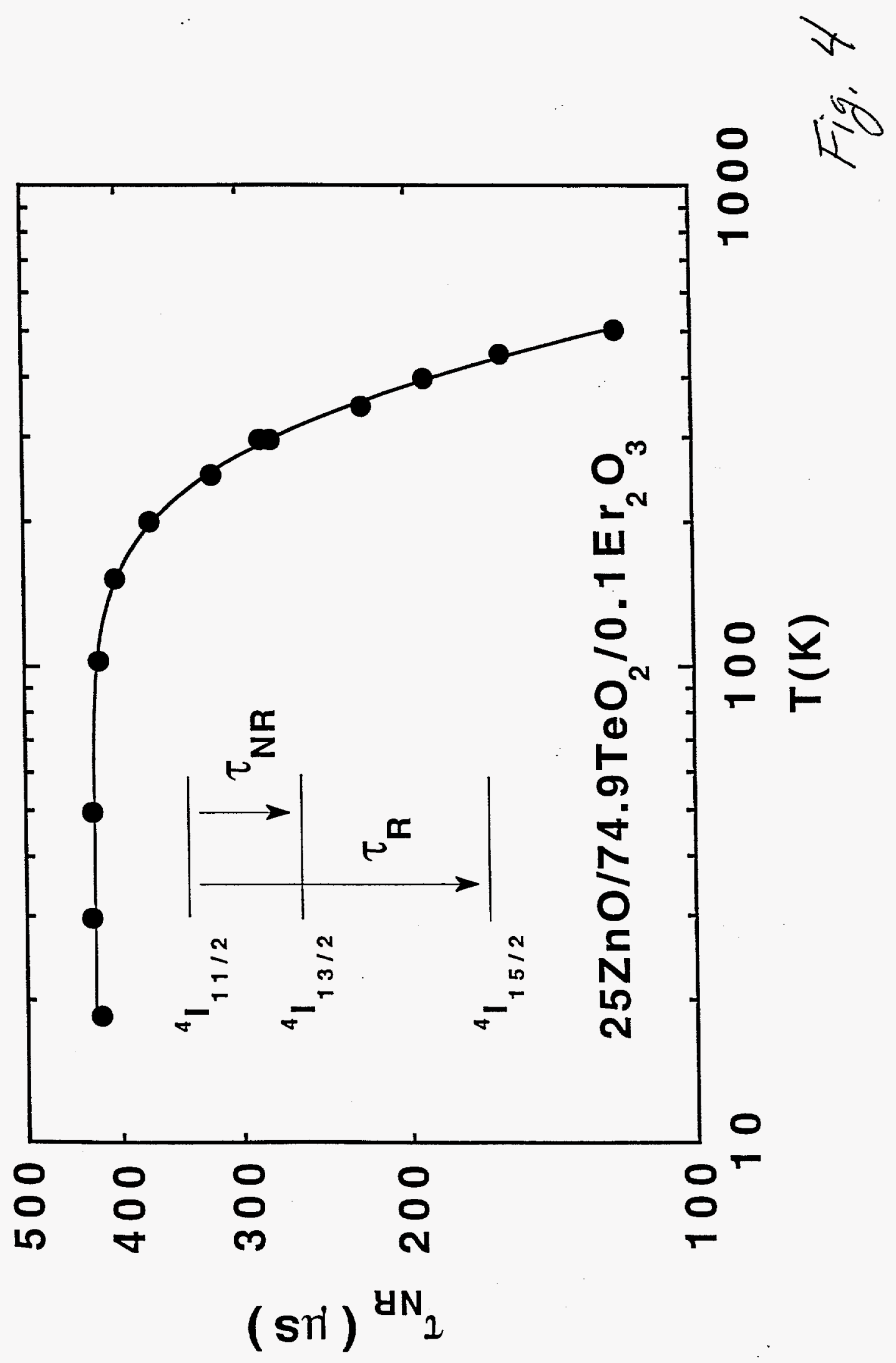




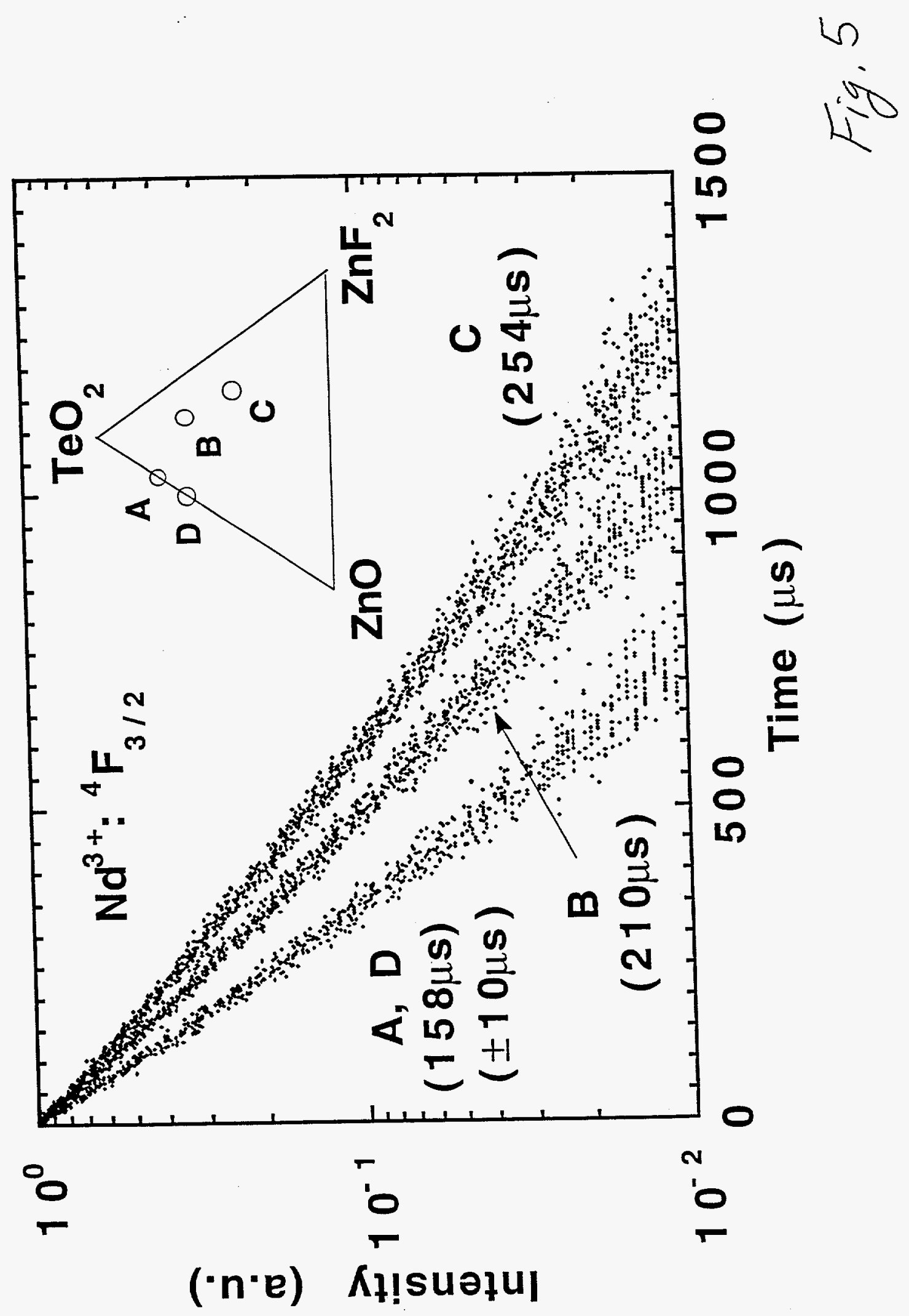

